\title{
EFFICIENCY OF THE PROGRESSIVE STRETCHING METHOD IN DEVELOPING FEMALE STUDENTS' FLEXIBILITY IN THE CHEERLEADING TEAM
}

\author{
Carmen GRIGOROIU ${ }^{1 *}$, Adrian PRICOP ${ }^{1}$ \\ ${ }^{1}$ Politehnica University of Bucharest, Faculty of Medical Engineering, Bucharest, Romania \\ *Corresponding author: carmen_grigoroiu2015@yahoo.com
}

https://doi.org/10.35189/dpeskj.2020.59.1.8

\begin{abstract}
The aim of the study is to investigate the possibilities of developing joint and muscular flexibility by highlighting the effects of special stretching programs applied through the progressive method on the group of subjects included in the research. The research was carried out on 14 subjects aged between 18 and 20, female students in the first and second years at the Politehnica University of Bucharest. The experiment was conducted within the training lessons of the cheerleading team for 7 months, between November 2018 and May 2019. During the mentioned period, five programs focused on stretching exercises were developed and applied in the preparation of the experimental group, in order to develop the mobility and joint flexibility of the spine and the coxofemoral area. The exercises were designed according to the age, the level of preparation and the biomotor potential of the female students. The exercise structures were performed in the first part of the training lesson, after a preliminary warm-up, for 15-20 minutes, three times a week. The analysis and interpretation of the experimental data resulting from the application of tests to assess the level of joint flexibility in female students have shown progress during the three tests (initial, intermediate and final), which attests the effectiveness of the progressive stretching method.
\end{abstract}

Keywords: flexibility, mobility, progressive stretching, female students.

\section{Introduction}

Competitive cheerleading includes a complex system of technical elements from acrobatic gymnastics (tumbling, stunts, pyramids, etc.), elements of rhythmic and aerobic gymnastics, figures and specific elements of any style of dance, all performed on the musical rhythm. In order to complete the contest program, cheerleaders need good physical training oriented to the development of strength, endurance, speed of execution, segmental and multi-segmental coordination, static and dynamic balance, capacity of spatial-temporal orientation, etc., but also of grace, elegance in movement, rhythm and musicality.

From an artistic point of view, obtaining a wide, fluid, plastic and expressive form of movement is a wish that depends on the level of development of joint flexibility and muscular elasticity. The amplitude of the movement is ensured by the offer of joint mobility, which must be maximum at all joints (Macovei, 1999, p. 24). It is suggested that flexibility is "the range of motion of a joint or a series of joints that are influenced by muscles, tendons, ligaments, bones, and bony structures" (Anderson \& Burke, 1991).

In cheerleading competitions, the shape and amplitude of the movement represents an evaluation criterion of the technical execution. Failure to observe the amplitude and form of the movement entails penalizing the team in the competition. The existing studies show that an increased value of articular suppleness provides the female athletes with superior skills of 
execution, the possibility of approaching a richer motor repertoire, as well as the increase of the chances of sport success (Macovei, 1999, p. 23).

Based on these considerations, we deemed it appropriate to investigate the intermediate motor ability - flexibility (mobility) from the perspective of optimizing its level of manifestation, as a qualitative basis for proper technical learning and execution, an aspect that will lead to the improvement of future sports performance.

Among the modalities for developing joint mobility and muscular flexibility, the most common is that of stretching exercises. Stretching is a common activity used by athletes, older adults, rehabilitation patients, and anyone participating in a fitness program (Page, 2012). Stretching is an effective and verified method that allows flexibility training, offering more possibilities for stretching the muscles. Several types of stretching are presented in the specialized literature (Damian, 2003, pp. 25-29):

- Static or passive stretching - is performed not by own muscular strength but also with an external force (partner, another body segment or own body weight);

- Dynamic stretching - is done by slow voluntary movements of the involved segment, gradually increasing the amplitude and the speed of execution;

- Active stretching - is also performed by voluntary movement to reach the maximum amplitude in movement, position in which the segment is maintained 10-15 seconds by the contraction of the agonist muscles and relaxation of the antagonist ones;

- Isometric stretching - is the combination of static stretching with an isometric contraction in the passive stretching position (performed with partner);

- PNF (proprioceptive neuromuscular facilitation) stretching - combines passive and isometric stretching for maximum static flexibility;

- Ballistic stretching - performed actively with the use of stretched muscle as a spring that will "throw" the working part of the body in the opposite direction;

- Progressive stretching - has as its mechanism of action the automatic neuromuscular reprogramming systems at the level of the neuromotor reflex arc. (Şalgău, 2005)

Stretching exercises are based on certain rules such as: the preliminary warming-up of the body (5-10 $\mathrm{min}$ ); the application of stretching means in the introductory, fundamental part or at the end of a more demanding training; the stretching will be slow, gradual, without any sudden movement, and the position will be kept until the targeted muscle relaxes; the position will be maintained without making arching movements; the breathing will be regular, rhythmic; feeling the pain will require to immediately stop the action (Petcu, 2019, p. 30).

Although the benefits of stretching are very well known, there is controversy as to which would be the most effective type of stretching. Some authors have compared static to dynamic stretching, both of which prove equally effective in the range of motion (De Weijer, Gorniak, \& Shamus, 2003; Young et al., 2004; Curry et al., 2009; Beedle \& Mann, 2007), while other authors did not find any performance improvement by comparing the two types of stretching (Wallmann, Mercer, \& Landers, 2008; McMillian et al., 2006; Dalrymple et al., 2010; Torres et al., 2008). However, it is recognized that static, dynamic and isometric stretching are effective methods of improving joint and muscle flexibility (Page, 2012). Passive stretching is more effective than dynamic stretching. The efficiency of different 
protocols such as timing of rest periods, placement within a workout schedule and repeated passive stretching have also showed good results (Gremion, 2005).

A less studied method is that of progressive stretching, which is why we chose to use it in this research. Progressive stretching is a method used by some Chinese athletes and is based on a program consisting of 3 series of 10 stretches (tension to the most accentuated sensation of pain) of the targeted muscles, which is followed by breaks equal in duration with the preceding stretch time. For example, the first series lasts: 6" tension - 6" break; 6" tension 6" break; 7" tension - 7" pause; 7" tension - 7" pause; 8" tension - 8" break; 8" tension - 8" break; 9" tension - 9" break; 9" tension - 9" break; 10" tension - 10" break; 10" tension, reaching the end of the third series at 20" tension - 20" break. The break between the first and second series is active, with the relaxation of the targeted muscles, and lasts between 30 " and 45", and between the second and third series, it is 45"-1' (Șalgău, 2005).

We consider that the topic addressed is up to date, since we have identified, during the practical activity carried out in the training lessons with the cheerleading team of the Politehnica University of Bucharest, the necessity to introduce programs focused on exercises to develop joint flexibility, tailored to the needs and level of preparation of the female students. Therefore, we found it appropriate to conduct this research, which would highlight the efficiency of the progressive stretching method and the impact of the designed programs applied to the subjects included in the research.

\section{Methodology}

In conducting the research, we have started from the premise that determining the initial level of coxofemoral and spinal flexibility in the investigated subjects will provide us with useful information for designing specific stretching programs with an important contribution to the improvement of the specific parameters.

The purpose of the study is to investigate the possibilities of developing the general joint and muscle flexibility by highlighting the effects of the special stretching programs applied by means of the progressive method on the group of subjects included in the research.

Objectives and tasks:

- determining the level of development of the coxofemoral and spinal flexibility after applying the designed programs;

- highlighting the efficiency of the progressive stretching method materialized in improved indices of joint flexibility.

In order to fulfill the proposed objectives, the following tasks were considered:

- establishing a system of operational structures and strategies for developing coxofemoral and spinal flexibility;

- designing the training process;

- experimenting the developed training programs;

- monitoring the progress of the experiment;

- carrying out the intermediate and final testing by applying the tests for the assessment of joint flexibility;

- verifying the dynamics of the results obtained by the experimental group and its statistical significance; 
- highlighting the efficiency of the proposed method in the stretching programs;

- drawing conclusions from the activity carried out.

Hypothesis

Using the progressive stretching method in the training exercises of students facilitates the development of joint mobility and muscle elasticity.

By developing and including in the training exercises some programs that aim to develop joint flexibility and muscle elasticity, we can contribute to improving the content and methodological efficiency in the preparation of female students.

\section{Methods}

In carrying out the present study, we used the following data collection methods: the method of bibliographic documentation, the observation method. The experiment was of longitudinal, ascertaining type.

\section{Participants}

The research was conducted on 14 subjects aged between 18 and 20, female students in the first and second years at the Politehnica University of Bucharest (UPB). Subject selection was performed at random.

\section{Instruments}

The working hypothesis was verified within the pedagogical experiment through the following tests used to assess:

- The spinal flexibility in the anterior plane. From the position sitting on the edge of a podium, with the legs close together and knees extended, the trunk was bent forward, touching the attached graded ruler with the fingertips. The position was maintained at the maximum point of bending of the trunk for 10 seconds. The distance in $\mathrm{cm}$ between the tiptoes and the fingertips was measured.

- The coxofemoral flexibility by performing the split on the floor with the right and left legs. The subjects performed the forward split on the floor to the point of discomfort, maintaining the position for 10", followed by 5 " of rest, repeated four times on each leg. With the help of the ruler, the distance between the anterior superior iliac spine and the floor was measured. The lower the anterior superior iliac spine, the lower the split and the better the performance (Sands et al., 2006).

\section{Procedure}

The place of the research was the gym of the UPB Sports Complex. The female students participated voluntarily in the research. At the beginning of the experiment, they were explained the particularities of the testing and the assessment techniques used, and they 
expressed their agreement in this regard. The research respected the ethical and medical conditions of the subjects' participation.

The experiment was conducted within the training lessons of the cheerleading team for 7 months, between November 2018 and May 2019.

The research stages were the following:

- between 5.11. - 9.11. 2018, the initial testing took place;

- between 12.11.2018 and 9.05.2019, the independent variable was applied to the experimental group, namely the joint and muscle flexibility training program;

- between 18.03. - 21.03.2019, the intermediate testing was carried out for the purpose of verifying the working techniques;

- between 06.05. - 9.05.2019, the final testing took place.

During the above-mentioned period, five programs focused on stretching exercises were designed and applied in the preparation of the experimental group, in order to develop the flexibility and articular suppleness of the spine and coxofemoral area. The exercises were designed according to the age, the level of preparation and the biomotor potential of the students. The exercise structures were performed in the first part of the training lesson, after a preliminary warm-up, for 15-20 minutes, three times a week.

The method used in performing the exercises was that of the progressive stretching, by means of which the grading of the intensity and time of maintaining the stretching positions, as well as of the breaks between series, was done. Basically, within each program, 3 series of 10 stretches of the targeted muscle groups were performed, followed by breaks equal as duration to the previous stretching time. Each stretching position was performed until bearable pain appeared.

We exemplify one of the stretching exercise programs for the development of coxofemoral mobility, which was applied in the training of the experimental group:

Program no. 1

Operational objective: optimization of joint mobility with emphasis on developing coxofemoral flexibility.

Teaching strategy:

- Materials: mattresses, fixed stairs, stopwatch;

- Training methods: demonstration, explanation, practice, conversation;

- Exercise methods: progressive stretching.

Operational structures:

1. Initial position: standing with feet close together, arms close to the body.

Large forward lunge on the right foot, $90^{\circ}$ angle between thigh and calf, palms resting on the knees, straight back;

Large forward lunge on the left foot, $90^{\circ}$ angle between thigh and calf, palms resting on the knees, straight back.

2. Initial position: standing with feet close together, arms close to the body.

Lateral lunge on the right foot, $90^{\circ}$ angle between thigh and calf, palms resting on the knees, straight back;

Lateral lunge on the left foot, $90^{\circ}$ angle between thigh and calf, palms resting on the knees, straight back. 
3. Initial position: standing with feet close together, arms close to the body.

Large forward lunge on the right foot, thigh resting on the calf, palms resting on the ground, trunk bent on the front foot, left foot with the sole in flexion;

Large forward lunge on the left foot, thigh resting on the calf, palms resting on the ground, trunk bent on the front foot, right foot with the sole in flexion.

4. Initial position: standing with feet apart, soles on the same line, arms close to the body.

Bending the trunk forward with the legs stretched, the sole of the right foot in flexion held with both hands;

Bending the trunk forward with the legs stretched, the sole of the left foot in flexion held with both hands.

5. Initial position: supine, legs stretched.

Moving the right foot held with both hands by the ankles in large gap ahead;

Moving the left foot held with both hands by the ankles in large gap ahead.

6. Sitting with feet apart, palms on the ground.

Leaning the trunk forward, palms on the ground, knees stretched;

Leaning the trunk forward, palms on the ground, knees bent.

7. Standing facing the fixed ladder, the foot raised to $90^{\circ}$ supported on the tip of the fixed ladder lath.

Leaning the trunk forward while keeping the knees stretched, palms resting on the ankle of the right/left foot.

8. Standing with the right/left shoulder towards the fixed ladder, the foot raised to $90^{\circ}$ supported on the tip of the fixed ladder lath.

Leaning the trunk laterally while keeping the knees stretched, palms resting on the ankle of the right/left foot.

9. Standing with the back towards the fixed ladder, the foot raised to $90^{\circ}$ resting on the tip of the fixed ladder lath, palms on the hips.

Demi-plie on the right/left foot with the straight back, eyes looking forward.

10. Forward/lateral split on the floor with the right/left tiptoe supported on the tip of the first lath of the fixed ladder.

\section{Results}

The data processing method was the statistical-mathematical one, through which the following statistical indicators were calculated: arithmetic mean, standard deviation, coefficient of variation. To validate the experimental hypothesis, the dependent t-test was used to highlight the differences between the tests following the application of the same independent variable to a single sample.

According to Fisher's table, critical t-test value for $n=13$, critical t-value $=2.16$ ( $\mathrm{p}<$ 0.05 ), critical $\mathrm{t}=3.01$ at the $\mathrm{p}$-value $<0.01$ and critical $\mathrm{t}=4.22$ at the $\mathrm{p}$-value $<0.001$.

The statistical values were calculated with EXCEL program, version 2007, of Microsoft.

The synoptic presentation of the recorded data was performed using the graphical method. Through this method, we represented each test applied during the assessment to provide a synthetic image of the value stage regarding the progress or regression of the investigated subjects. 
Tables 1, 2 and 3 show the dynamics of the results obtained from the three tests (initial, intermediate and final), comparing the values of the parameters determined by tests assessing the flexibility of the spine and coxofemoral area at the group level, within the framework of the determined statistical indicators: arithmetic mean ("X"), standard deviation (" $\sigma$ "), coefficient of variation $(\mathrm{Cv} \%)$, dependent t-test. The evolution of the arithmetic mean for the experimental group, as well as the dynamics of individual results obtained during the experiment are graphically represented in Figures 1-6.

Table 1. Comparative analysis of the results obtained by the experimental group in the assessment of spinal flexibility - Initial test (T1) and intermediate test (T2)

\begin{tabular}{|c|c|c|c|c|c|c|c|}
\hline \multirow{2}{*}{ TEST } & \multicolumn{7}{|c|}{ STATISTICAL-MATHEMATICAL INDICATORS } \\
\hline & $\overline{\mathrm{X}} / \pm \sigma$ & $\overline{\mathrm{X}} / \pm \sigma$ & PROGRESS & $\mathrm{Cv}$ & & $t$ & $n$ \\
\hline & $\mathrm{T} 1$ & $\mathrm{~T} 2$ & T1-T2 & T1 & $\mathrm{T} 2$ & 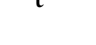 & $P$ \\
\hline Spinal flex. & $24.07 / \pm 3.57$ & $24.71 / \pm 3.17$ & 0.64 & 14.85 & 12.83 & 2.09 & $>0.05$ \\
\hline & & $22.5 / \pm 1.63$ & 1.07 & 6.93 & 7.65 & 6.51 & $<0.001$ \\
\hline Flex. right $\mathrm{f}$. & $19.43 / \pm 2.53$ & $17.43 / \pm 2.68$ & 2,00 & 13.02 & 15.37 & 11.01 & $<0.001$ \\
\hline
\end{tabular}

Table 2. Comparative analysis of the results obtained by the experimental group in the assessment of spinal flexibility - Intermediate test (T2) and final test (T3)

\begin{tabular}{llllllll}
\hline \multicolumn{1}{l}{ STATISTICAL-MATHEMATICAL INDICATORS } \\
\hline TEST & $\overline{\mathrm{X}} / \pm \sigma$ & $\overline{\mathrm{X}} / \pm \sigma$ & PROGRESS & $\mathrm{Cv}$ & & $\mathrm{t}$ & $\mathrm{p}$ \\
& $\mathrm{T} 2$ & $\mathrm{~T} 3$ & $\mathrm{~T} 2-\mathrm{T} 3$ & $\mathrm{~T} 2$ & $\mathrm{~T} 3$ & & \multicolumn{1}{c}{} \\
Spinal flex. & $24.71 / \pm 3.17$ & $28.07 / \pm 2.95$ & 3.36 & 12.83 & 10.50 & 10.00 & $<0.001$ \\
Flex. left f. & $22.5 / \pm 1.63$ & $20.5 / \pm 1.72$ & 2 & 7.65 & 8.39 & 11.01 & $<0.001$ \\
Flex. right f. & $17.43 / \pm 2.68$ & $15.00 / \pm 2.88$ & 2.43 & 15.37 & 19.20 & 14.06 & $<0.001$ \\
\hline
\end{tabular}

Table 3. Comparative analysis of the results obtained by the experimental group in the assessment of spinal flexibility - Initial test (T1) and final test (T3)

\begin{tabular}{llllllllc}
\hline \multicolumn{7}{l}{ STATISTICAL-MATHEMATICAL INDICATORS } \\
\hline \multirow{2}{*}{ TEST } & $\overline{\mathrm{X}} / \pm \sigma$ & $\overline{\mathrm{X}} / \pm \sigma$ & PROGRESS & $\mathrm{Cv}$ & & $\mathrm{t}$ & $\mathrm{p}$ \\
& $\mathrm{T} 1$ & $\mathrm{~T} 3$ & $\mathrm{~T} 1-\mathrm{T} 3$ & $\mathrm{~T} 1$ & $\mathrm{~T} 3$ & & \multicolumn{1}{c}{} \\
Spinal flex. & $24.07 / \pm 3.57$ & $28.07 / \pm 2.95$ & 4 & 14.85 & 10.50 & 10.58 & $<0.001$ \\
Flex. left $\mathrm{f}$. & $23.57 / \pm 1.63$ & $20.5 / \pm 1.72$ & 3.07 & 6.93 & 8.39 & 11.52 & $<0.001$ \\
Flex. right f. & $19.43 / \pm 2.53$ & $15.00 / \pm 2.88$ & 4.43 & 13.02 & 19.20 & 17.67 & $<0.001$ \\
\hline
\end{tabular}

We find that, for the spinal flexibility test (Tables 1-3), the value of the arithmetic mean "X" (Figure 1) is $24.07 \mathrm{~cm}$ in the initial test (T1), $24.71 \mathrm{~cm}$ in the intermediate test (T2), and $28.07 \mathrm{~cm}$ in the final test (T3). The progress rate between T1-T2 is $0.64 \mathrm{~cm}$, between T2-T3, $3.36 \mathrm{~cm}$, and between T1-T3, $4 \mathrm{~cm}$. The spreading degree of the string values represented by the standard deviation " $\sigma$ " has the following values: 3.57 in the initial test (T1), 3.17 in the intermediate test (T2), and 2.95 in the final test (T3). The coefficient of variation " $\mathrm{Cv}$ " has the value of $14.85 \%$ in the initial test (T1), $12.83 \%$ in the intermediate test (T2), and $10.50 \%$ in the final test (T3), therefore the dispersion is average, and the sample is relatively homogeneous in all three tests. The Student's calculated t-value between T1-T2 is 2.09, so $2.09<2.16$ (for $\mathrm{p}<0.05$ ), meaning that there are no significant differences between the 
means of the two tests. The t-value between T2-T3 is 10, and between T1-T3, 10.58, so there is a significant difference between these tests for $\mathrm{p}<0.001$.

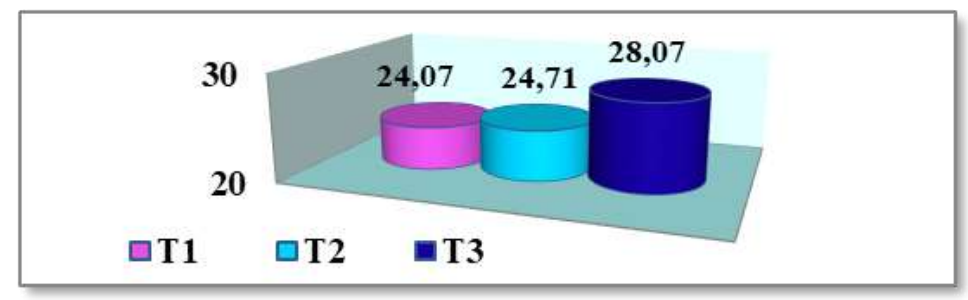

Figure 1. Dynamics of the experimental group in the spinal flexibility test (T1, T2, T3)

Figure 2 shows that all subjects have progressed during the three tests.

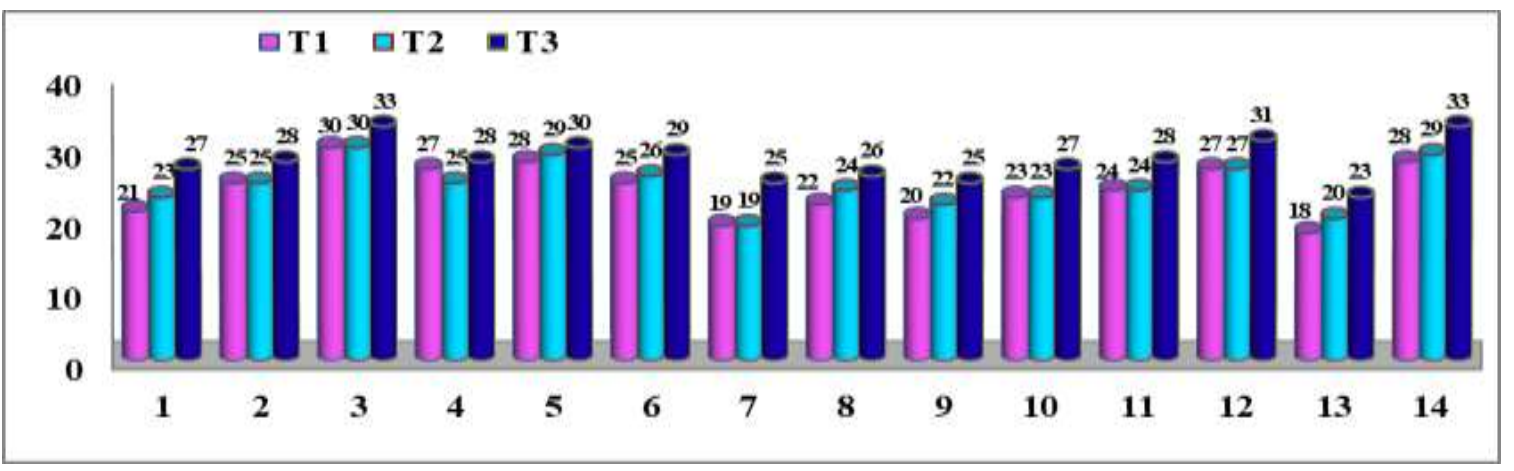

Figure 2. Individual dynamics in the spinal flexibility test (T1, T2, T3)

For the left-leg split test (Tables 1-3), the value of the arithmetic mean " $\mathrm{X}$ " (Figure 3) is $23.57 \mathrm{~cm}$ in the initial test (T1), $22.5 \mathrm{~cm}$ in the intermediate test (T2), and $20.5 \mathrm{~cm}$ in the final test (T3). The progress rate between T1-T2 is $1.07 \mathrm{~cm}$, between T2-T3, $2 \mathrm{~cm}$, and between $\mathrm{T} 1-\mathrm{T} 3,3.07 \mathrm{~cm}$.

The spreading degree of the string values represented by the standard deviation " $\sigma$ " has the following values: 1.63 in the initial (T1) and intermediate (T2) tests, and 1.72 in the final test (T3). The coefficient of variation " $\mathrm{Cv}$ " has the value of $6.93 \%$ in the initial test (T1), $7.65 \%$ in the intermediate test (T2), and $8.39 \%$ in the final test (T3), so the dispersion is small, and the homogeneity is high in all three tests.

The Student's calculated t-value between T1-T2 is 6.51, between T2-T3, 11.01, and between T1-T3, 11.52. Since 6.51, 11.01 and $11.52>4.22$ (for $p<0.001$ ), the differences between these tests are significant. 


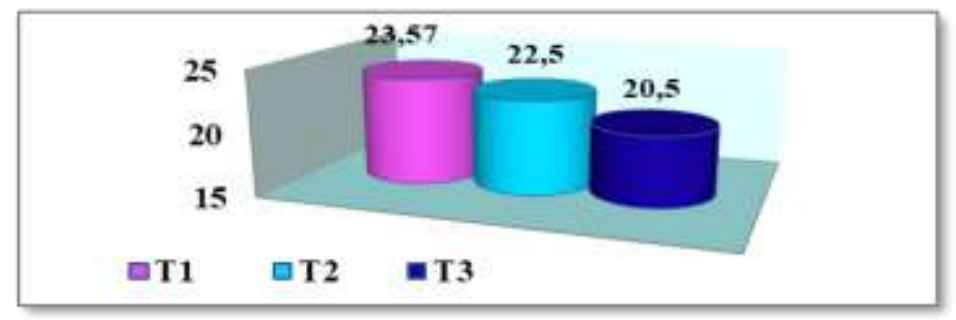

Figure 3. Dynamics of the experimental group in the left-leg split test (T1, T2, T3)

Figure 4 suggestively illustrates the individual dynamics of the subjects in this test. We find that $100 \%$ of the subjects (14 subjects) have made progress during the three tests.

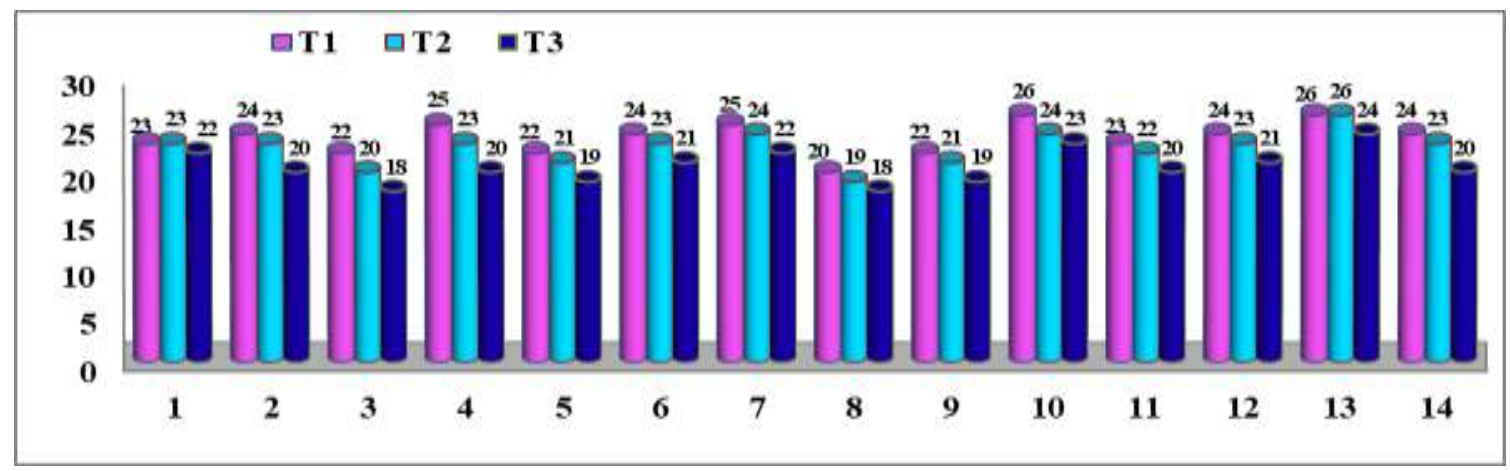

Figure 4. Individual dynamics in the left-leg split test (T1, T2, T3)

For the right-leg split test (Tables 1-3), the value of the arithmetic mean " $X$ " (Figure 5) is $19.43 \mathrm{~cm}$ in the initial test (T1), $17.43 \mathrm{~cm}$ in the intermediate test (T2), and $15.00 \mathrm{~cm}$ in the final test (T3). The progress rate between T1-T2 is $2 \mathrm{~cm}$, between T2-T3, $2.43 \mathrm{~cm}$, and between T1-T3, $4.43 \mathrm{~cm}$. The spreading degree of the string values represented by the standard deviation " $\sigma$ " has the following values: 2.53 in the initial test (T1), 2.68 in the intermediate test (T2), and 2.88 in the final test (T3). The coefficient of variation " $\mathrm{Cv}$ " has the value of $13.02 \%$ in the initial test (T1), $15.37 \%$ in the intermediate test (T2), and $19.20 \%$ in the final test (T3), so the dispersion is small, and the homogeneity is high in all three tests. The Student's calculated t-value between T1-T2 is 11.01, between T2-T3, 14.06, and between T1-T3, 17.67. Since 11.01, 14.06 and $17.67>4.22$ (for $p<0.001$ ), the differences between these tests are significant.

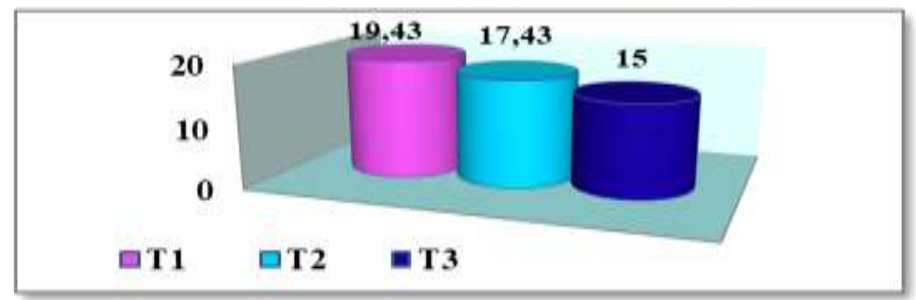

Figure 5. Dynamics of the experimental group in the right-leg split test (T1, T2, T3) 
Figure 6 suggestively illustrates the individual dynamics of the subjects in this test. We find that $100 \%$ of the subjects (14 subjects) have made progress during the three tests.

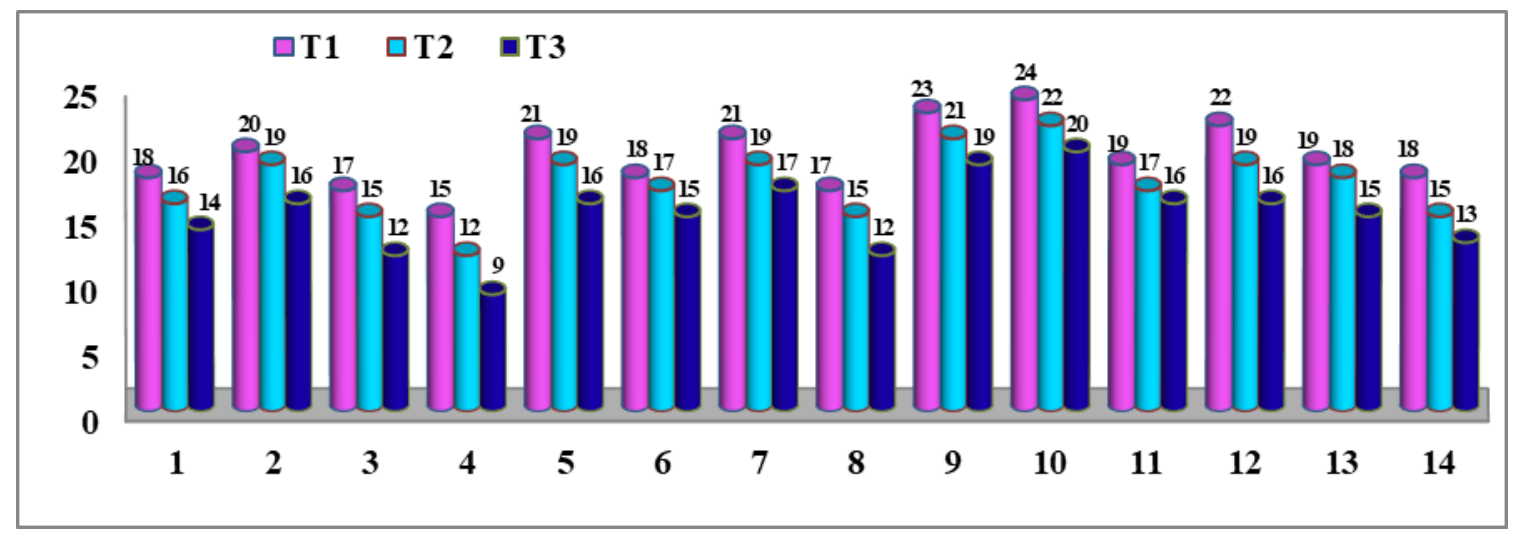

Figure 6. Individual dynamics in the right-leg split test (T1, T2, T3)

\section{Discussion}

The theoretical analysis and generalization of the experimental data allowed establishing the effective influence of the progressive stretching method on the development of flexibility in the coxofemoral joint and the spine after the 7 months of training performed by the investigated subjects.

According to the data available in the literature, there are three established stretching methods used to develop flexibility: ballistic stretching, static stretching, and proprioceptive neuromuscular facilitation techniques, but it is not possible to determine exactly which of them is the most effective (Roberts \& Wilson, 1999). Previous studies have shown that proprioceptive neuromuscular facilitation techniques increase flexibility more than static stretching (Sharman, Cresswell, \& Riek, 2006), but the simultaneous use of proprioceptive neuromuscular facilitation techniques and static stretching has improved flexibility more than dynamic stretching (Tolliver et al., 2017; Lempke et al., 2018).

The progressive stretching method, which is based on grading the intensity and time of the actions and breaks, is less used because it needs to be allocated a longer time during the workouts/lessons. Compared to other stretching methods, this involves tightening the muscles against a background of increased pain, but it is effective in combating muscle fever and improving the recovery process in the case of muscular micro-injuries (Șalgău, 2005).

In this study, we intended to investigate the efficiency of this method in developing the joint and muscle flexibility of female students aged 18-20. The analysis and interpretation of the experimental data resulting from the application of tests to assess the level of joint flexibility in female students have highlighted the validity of the teaching strategy, which confirms the hypotheses of the research.

The improvement of joint flexibility and muscle elasticity indices during the three tests (initial, intermediate and final) emphasizes the efficiency of the progressive stretching method. 
We believe that the information on the level of joint flexibility is an important benchmark in designing the teaching strategy and applying it in the training sessions.

The rationalization and standardization of stretching exercises in the form of programs adapted to the level of preparation and the age of female students, as well as their judicious application in the training, have contributed to improving the content and methodological efficiency of the workouts.

The topic addressed in this study may be a starting point in carrying out further research on the efficiency of the progressive stretching method as compared to other methods for the development of flexibility.

This research has some limitations such as:

- the participants are young female students, and therefore the findings cannot be generalized to all populations;

- the small number of subjects participating in the experiment;

- the restricted area of applicability (cheerleading).

\section{Conclusion}

The advantage of the method used was the grading of the intensity and time of the exercises performed, which allowed control and precision by removing the rigidity of the execution and the unjustified muscle tension.

Developing specialized and accessible stretching programs has led to the active and conscious participation of students in the training lessons.

Using stretching exercises and the progressive method in the training process of female students aged 18-20 considerably complements the data existing in the literature.

By developing joint and muscle flexibility, some aspects related to the correctness in the execution of technical elements specific to cheerleading can be solved and implicitly the sports performance is improved.

\section{Acknowledgements}

The authors would like to thank cheerleaders for their participation in this research study.

\section{Authors' contributions}

All authors have equally participated in this study and should be considered as main authors.

\section{References}

Anderson, O., \& Burke, E.R. (1991). Scientific, medical, and practical aspects of stretching. Clinics in Sports Medicine, 10(1), 63-86. PMID: 2015647

Beedle, B. B., \& Mann C. L. (2007). A comparison of two warm-ups on joint range of motion. Journal of Strength and Conditioning Research, 21(3), 776-779. doi:10.1519/R19415.1 
Curry. B. S., Chengkalath, D., Crouch, G. J., Romance, M., \& Manns, P. J. (2009). Acute effects of dynamic stretching, static stretching, and light aerobic activity on muscular performance in women. Journal of Strength and Conditioning Research, 23(6), 18111819. doi:10.1519/JSC.0b013e3181b73c2b

Dalrymple, K. J., Davis, S. E., Dwyer, G. B., \& Moir, G. L. (2010). Effect of static and dynamic stretching on vertical jump performance in collegiate women volleyball players. Journal of Strength and Conditioning Research, 24(1), 149-155. doi:10.1519/JSC.0b013e3181b29614

Damian, Ş. (2003). Stretching, secretul flexibilităţii [Stretching, the secret of flexibility]. Bucureşti: Corint.

DeWeijer V. C., Gorniak G. C., \& Shamus E. (2003). The effect of static stretch and warmup exercise on hamstring length over the course of 24 hours. Journal of Orthopaedic \& Sports, 33(12), 727-733. doi: 10.2519/jospt.2003.33.12.727

Gremion, G. (2005). The effect of stretching on sports performance and the risk of sports injury: A review of the literature. Schweizerische Zeitschrift für Sportmedizin und Sporttraumatologie, 53(1), 6-10. Retrieved from https://sgsm.ch/fileadmin/user_upload/Zeitschrift/53-2005-1/3-2005-1.pdf

Lempke, L., Wilkinson, R., Murray, C., \& Stanek, J. (2018). The effectiveness of PNF versus static stretching on increasing hip-flexion range of motion. Journal of Sport Rehabilitation, 27(3), 289-294. doi: https://doi.org/10.1123/jsr.2016-0098

Macovei, S. (1999). Gimnastica ritmică de performanţă [Performance rhythmic gymnastics]. Bucureşti: ANEFS.

McMillian, D. J., Moore, J. H., Hatler, B. S., \& Taylor, D. C. (2006). Dynamic vs. staticstretching warm-up: The effect on power and agility performance. Journal of Strength and Conditioning Research, 20(3), 492-499. doi:10.1519/18205.1

Page, P. (2012). Current concepts in muscle stretching for exercise and rehabilitation. International Journal of Sports Physical Theraphy, 7(1), 109-119. PMID: 22319684

Petcu, C. I. (2019). Implicațiile programelor specifice de tonifiere musculară și stretching asupra organismului persoanelor cu atitudini deficitare, din perspectivă profilactică (Teză de doctorat) [Implications of the specific muscle toning and stretching programs on the body of people with deficient attitudes, from a prophylactic perspective - $\mathrm{PhD}$ thesis]. București: UNEFS.

Roberts, J. M., \& Wilson, K. (1999). Effect of stretching duration on active and passive range of motion in the lower extremity. British Journal of Sports Medicine, 33, 259-263. doi: 10.1136/bjsm.33.4.259

Sands, W., A., McNeal, J., R., Stone, M., H., Russell, E. M., \& Jemni, M. (2006). Flexibility enhancement with vibration: Acute and long-term. Medicine and Science in Sports \& Exercise, 38(4), 720-725. doi:10.1249/01.mss.0000210204.10200.dc

Sharman, M. J., Cresswell, A. G., \& Riek, S. (2006). Proprioceptive neuromuscular facilitation stretching: Mechanisms and clinical implications. Sport Medicine, 36, 929-939. doi: 10.2165/00007256-200636110-00002

Şalgău, S. (2005). Antrenamentul de flexibilitate la înotători [Flexibility training for swimmers]. Journal of Physical Education and Sport, 5(1), 30-35. Retrieved from http://efsupit.ro/images/stories/imgs/1\%202005.pdf

Tolliver, S., Drew, M., Kitts, K., Miller, F. L., \& Londono, Y. C. (2017). Static stretching and proprioceptive neuromuscular facilitation stretching within collegiate athletes. International Journal of Research in Exercise Physiology, 12(2), 22-27. Retrieved from https://pdfs.semanticscholar.org/a714/b45ff7d82a5d84be09eec1910967c464386b.pdf?_ga $=2.189988651 .1835199796 .1585668710-2002873115.1585668710$ 
Torres, E. M., Kraemer, W. J., Vingren, J. L., Volek, J. S., Hatfield, D. L., Spiering, B. A., ... Maresh, C. M. (2008). Effects of stretching on upper-body muscular performance. Journal of Strength and Conditioning Research, 22(4), 1279-1285. doi: 10.1519/JSC.0b013e31816eb501

Wallmann, H. W., Mercer, J. A., \& Landers, M. R. (2008). Surface electromyographic assessment of the effect of dynamic activity and dynamic activity with static stretching of the gastrocnemius on vertical jump performance. Journal of Strength and Conditioning Research, 22(3), 787-793. doi: 10.1519/JSC.0b013e3181660e27

Young, W., Clothier, P., Otago, L., Bruce, L., \& Liddell, D. (2004). Acute effects of static stretching on hip flexor and quadriceps flexibility, range of motion and foot speed in kicking a football. Journal of Science and Medicine in Sport, 7(1), 23-31. doi:10.1016/s1440-2440(04)80040-9 